\title{
Mechatronics and Robotics Education: Standardizing Foundational Key Concepts
}

\author{
Kevin McFall \\ Kennesaw State University \\ Kevin Huang \\ Trinity College \\ Hunter Gilbert \\ Louisiana State University \\ Musa Jouaneh \\ University of Rhode Island \\ He Bai \\ Oklahoma State University \\ David Auslander \\ University of California, Berkeley
}

The field of Mechatronics and Robotics Engineering is emerging as a distinct academic discipline, but has no standardized curriculum. In order to define such a curriculum, a survey is prepared with lists of potential concept inventory items, and asks university faculty, students and practicing engineers to identify which concepts lie at the core of MRE. Because of the interdisciplinary nature of the field, a wide range of basic concepts including physical quantities and units, circuit analysis, digital logic, programming, computeraided design, solid mechanics, dynamic systems and controls, and mathematics are considered. The results of this survey identify gaps between existing undergraduate curricula, student experience, and employer expectations, and continuing work will provide insight into the direction of a unifying curricular design for MRE education.

Keywords: mechatronics, robotics, curriculum, key concepts, survey

\section{INTRODUCTION}

The field of Mechatronics (Auslander, 1996) and Robotics (Birk, 2011) Engineering (MRE) is emerging as a distinct academic discipline. Previously, courses in this field have been housed in departments of Mechanical Engineering, Electrical Engineering, or Computer Science, instead of a 
standalone department or curriculum (Alciatore \& Histand, 2001; Edward Lyshevski, 2002; Manseur, 1997). More recently, single, freestanding courses have increasingly grown into course sequences and concentrations, with entire baccalaureate and graduate degree programs now being offered (Craig \& Voglewede, 2010; Fletcher, 2014; Gennert \& Putnam, 2018; Hsu, 1999; Salami et al., 2003). The field has been legitimized in recent years with the National Center for Education Statistics creating the Classification of Instructional Programs (CIP) code 14.201 Mechatronics, Robotics, and Automation Engineering (National Center for Education Statistics, n.d.). As of October 2019, ABET accredits a total of 9 B.S. programs in the field: 5 Mechatronics Engineering, 3 Robotics Engineering, 1 Mechatronics and Robotics Engineering, and none in Automation Engineering.

Despite recent tremendous and dynamic growth, MRE lacks a dedicated professional organization and has no discipline-specific ABET criteria. As the field grows more important and widespread, it becomes increasingly relevant to formalize and standardize the curricula of these programs. This paper begins a conversation about the contents of a cohesive list of key concepts for MRE. The impetus for this effort grew from a set of four industry and government sponsored workshops held around the country named the Future of Mechatronics and Robotics Engineering (FoMRE). These workshops brought together multidisciplinary academic professionals and industry leaders in the field, and ran from September 2018 to September 2019.

The goal of this current work is to survey the MRE community to understand what science, mathematics, and engineering concepts are most vital to the burgeoning field of MRE. Like most engineering curricula, the limits of a typical 120 credit baccalaureate program constrain the amount of content that can be delivered in a program. And MRE programs especially, with their content ranging across mechanics, electronics, and computing, must make judicious decisions about which concepts are included and which are left out. The survey used in this study was designed to identify the relative importance of the many topics important to MRE in order to identify the fundamental key concepts that should be included in all MRE programs. While the study presented here focuses primarily on programs at the baccalaureate level, it also informs discussion at the graduate level as well.

\section{METHODS}

\section{Survey Distribution}

A survey was created in Google Forms and distributed via email and word-of-mouth. The survey was completely voluntary and no compensation was provided to participants. Potential self-selection bias should be noted; respondents who took the time to answer the survey are invested in mechatronics education in some way, and may be more or less inclined to believe change is necessary. Responses were collected for a period of 35 days, starting from the 19th of December, 2019 and closing on the 22nd of January, 2020. The study was approved by the Trinity College Institutional Review Board, and in total, 83 subjects responded to the survey.

As part of the survey, respondents were asked to identify their primary role. These roles are shown below in order of descending number of respondents. The relative percentage of respondents who identified with said role are also shown:

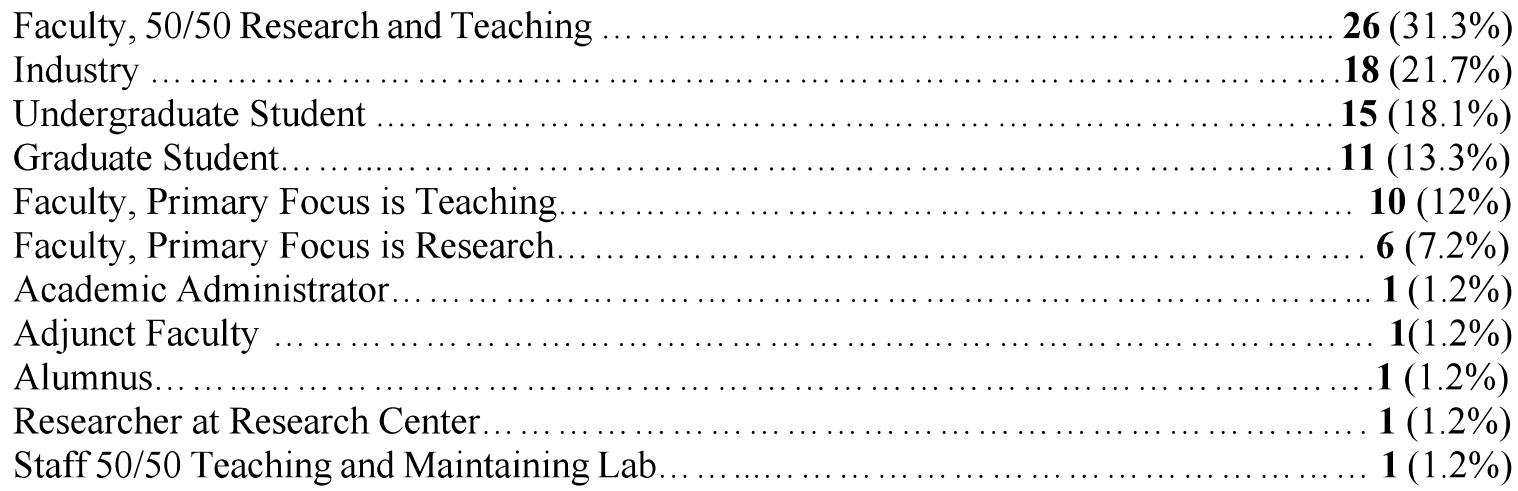


The respondents identified their primary fields of expertise as shown below in FIGURE 1

\section{FIGURE 1 \\ RESPONDENTS' FIELDS OF EXPERTISE. 39 RESPONDENTS IDENTIFIED WITH BOTH MECHATRONICS AND ROBOTICS, 23 WITH MECHATRONICS, 16 WITH ROBOTICS, AND 5 WITH NEITHER MECHATRONICS NOR ROBOTICS}

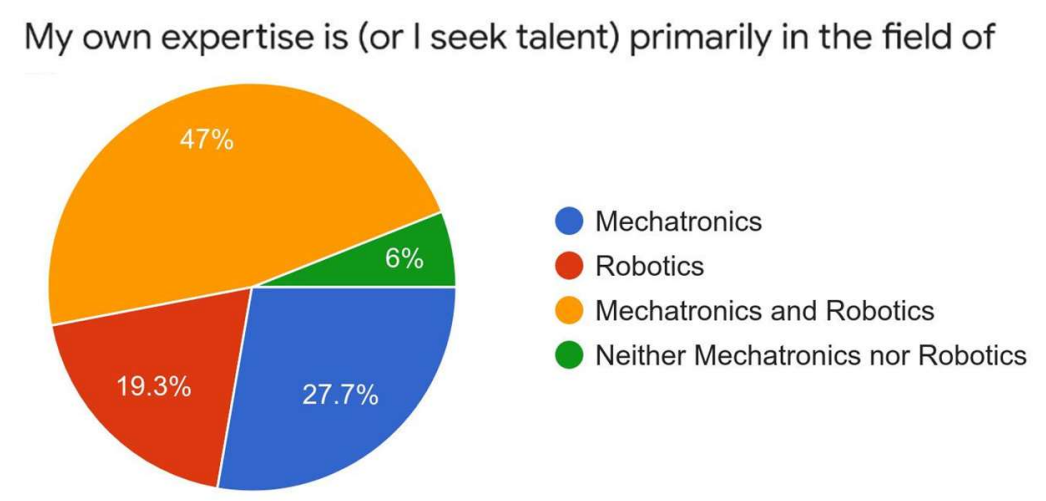

\section{Survey Questions}

Several types of questions were posed in the survey. Beyond the two questions requesting back- ground details (role and area of expertise), we asked participants in sequence four classes of queries. The classes targeted (we also show the number of questions within each class):

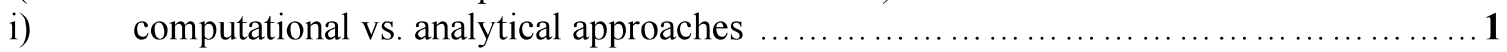

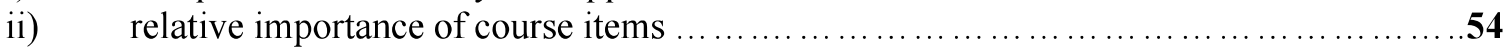

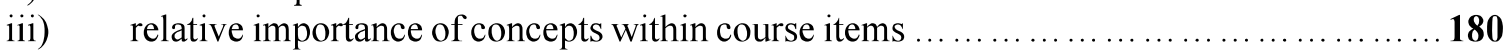

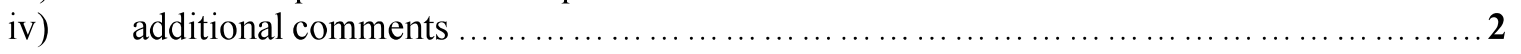

The question classes were presented to participants in the order shown above, for a total of 239 questions asked per participant - respondents were not required to answer all questions. The questions in classes i) - iii) were presented as Likert rating tasks. The question in class i) was shown as below in FIGURE 2.

\section{FIGURE 2}

\section{QUESTION ASKED TO PARTICIPANTS REGARDING THE RELATIVE IMPORTANCE OF COMPUTATIONAL VS. ANALYTICAL APPROACHES THAT SHOULD BE EMPHASIZED IN MECHATRONICS AND ROBOTICS CURRICULUM}

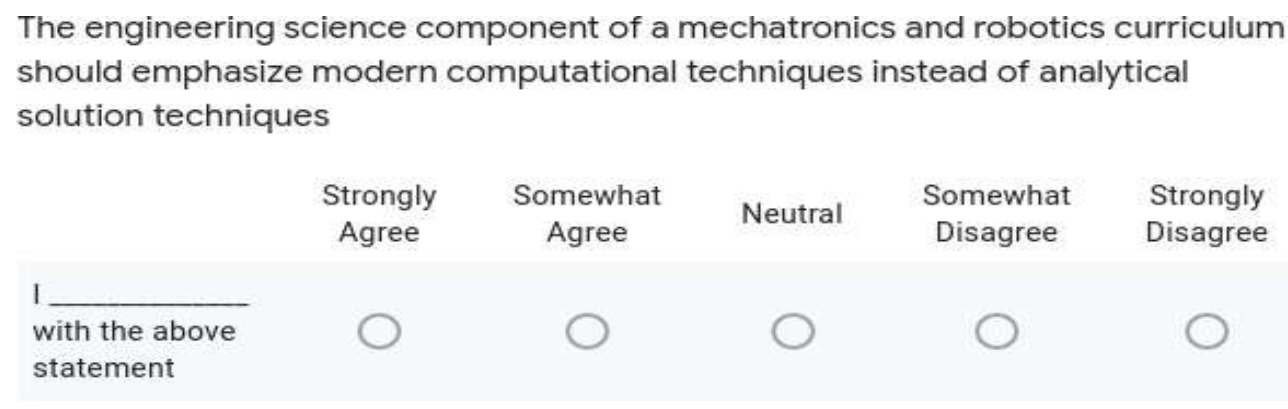

For questions in class ii), participants were tasked to "Please rank on a Likert scale the importance to mechatronics/robotics education of each of the following course items (1 least to 5 most important)". A sampling of the survey question format is shown below in FIGURE 3. 


\section{FIGURE 3}

\section{EXAMPLE LIKERT RATING TASKS PRESENTED TO USERS FOR EVALUATING}

IMPORTANCE OF COURSE ITEMS IN MECHATRONICS/ROBOTICS EDUCATION

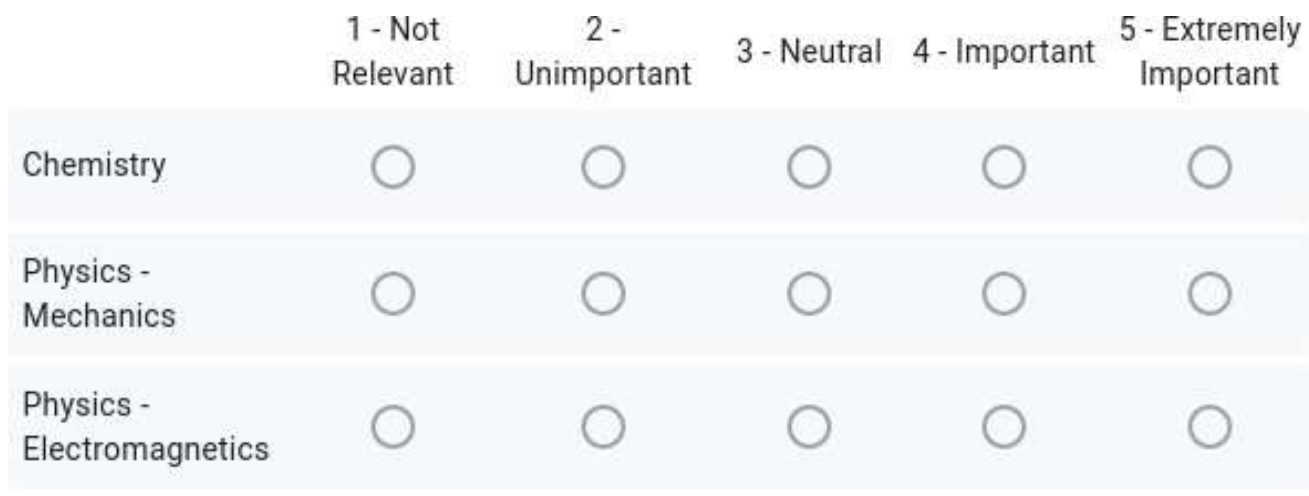

Class iii) questions asked participants to rank importance of concepts within course items on a Likert scale. Users were requested: "For each of the below course items you deem important, please rank on a Likert scale the importance of the listed concepts (1 least to 5 most important)". A sample of the concept Likert scale response format for a particular course item is shown below in FIGURE 4.

\section{FIGURE 4 \\ EXAMPLE LIKERT RATING TASKS PRESENTED TO USERS FOR EVALUATING IMPORTANCE OF CONCEPTS WITHIN A COURSE ITEM IN MECHATRONICS/ROBOTICS EDUCATION}

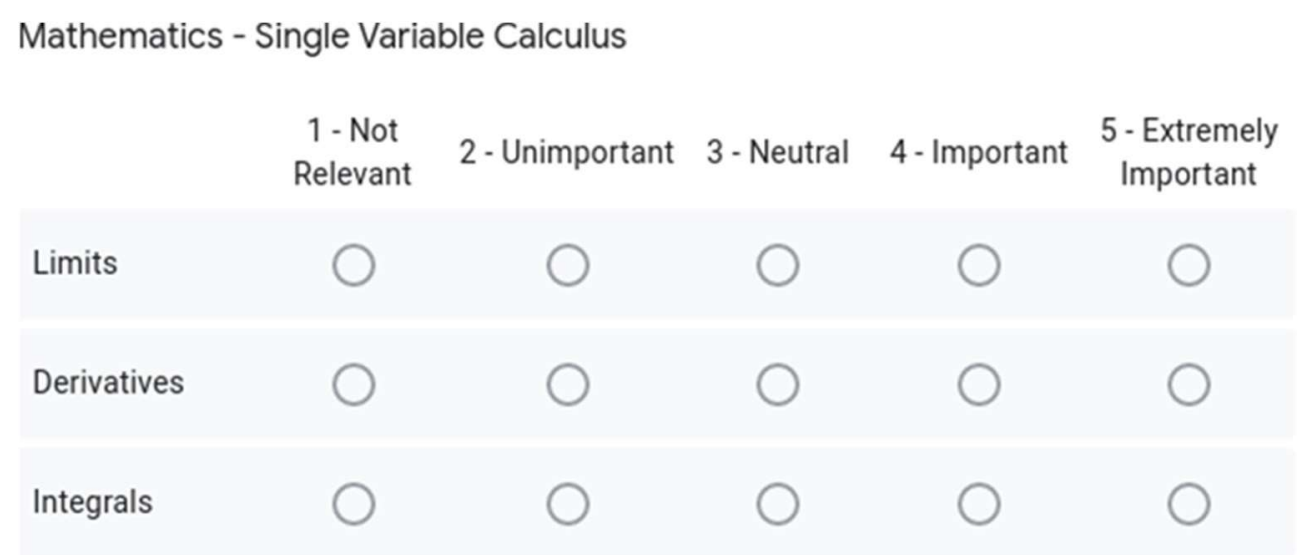

Finally respondents were asked to provide any additional comments or insight in the two class iv) type questions. These included:

1. "Are there any other concepts that you think we missed? How would you rank them?"

2. "Any additional thoughts about compiling key concepts for mechatronics and robotics education that you would like to share?"

\section{RESULTS AND ANALYSIS}

\section{Course Items That Were Rated Important or Extremely Important}

The ten course topics that received the highest combined rating by all the respondents as a percent- age of the five available choices for each topic were collected. TABLE 1 and FIGURE 5 show these data for all respondents. The data for the administrator group are not shown in TABLE 1 since there was only one 
respondent in that group. In general, there was not a substantial difference in the percentage rating among the different groups. In total $(n=83)$, the highest rated topic was rated highly by $99 \%$ of respondents, while the tenth ranked topic was rated highly by only $94 \%$. The highest ranked topic (PID control) was rated as important or extremely important by

i) $\quad 100 \%$ of the faculty group (total $n=39$ );

ii) $\quad 100 \%$ of the industry group (total $n=18$ );

iii) $\quad 92 \%$ of the undergraduate student group (total $n=15$ );

iv) $\quad 100 \%$ of the graduate student group (total $n=10$ );

while the tenth highest ranked topic (Serial Mechanisms) was rated as important or extremely important by

i) $\quad 91 \%$ of the faculty group (total $n=39$ );

ii) $\quad 94 \%$ of the industry group (total $n=18$ );

iii) $\quad 100 \%$ of the undergraduate student group (total $n=15$ );

iv) $100 \%$ of the graduate student group (total $n=10$ ).

TABLE 1

IMPORTANT COURSE TOPICS

\begin{tabular}{|c|c|c|c|c|c|}
\hline \multirow[t]{2}{*}{ Course[Topic] } & \multicolumn{5}{|c|}{$\begin{array}{l}\text { \% of Respondents Who Identify the Topic as Either Extremely } \\
\text { Important or Important }\end{array}$} \\
\hline & $\begin{array}{c}\text { All } \\
(n=83)\end{array}$ & $\begin{array}{l}\text { Faculty } \\
(n=39)\end{array}$ & $\begin{array}{l}\text { Industry } \\
(n=18)\end{array}$ & $\begin{array}{c}\text { Graduate } \\
\text { Students } \\
(n=10)\end{array}$ & $\begin{array}{l}\text { Undergraduate } \\
\text { Students }(n=15)\end{array}$ \\
\hline $\begin{array}{l}\text { Control Systems [PID } \\
\text { control] }\end{array}$ & 99 & 100 & 100 & 100 & 92 \\
\hline $\begin{array}{l}\text { Kinematics [Forward } \\
\text { Kinematics] }\end{array}$ & 99 & 100 & 94 & 100 & 100 \\
\hline $\begin{array}{l}\text { Control Systems } \\
\text { [Feedback Control] }\end{array}$ & 99 & 100 & 100 & 100 & 91 \\
\hline Kinematics [Gears] & 97 & 97 & 100 & 100 & 92 \\
\hline $\begin{array}{l}\text { Kinematics [Inverse } \\
\text { Kinematics] }\end{array}$ & 97 & 97 & 94 & 100 & 100 \\
\hline $\begin{array}{l}\text { Control Systems } \\
\text { [Frequency } \\
\text { Response] }\end{array}$ & 96 & 94 & 100 & 100 & 91 \\
\hline $\begin{array}{l}\text { Mathematics - Linear } \\
\text { Algebra [Systems of } \\
\text { Linear Equations] }\end{array}$ & 95 & 100 & 88 & 100 & 85 \\
\hline $\begin{array}{l}\text { Dynamics [Rigid Body } \\
\text { Kinetics] }\end{array}$ & 95 & 97 & 94 & 90 & 93 \\
\hline $\begin{array}{l}\text { Control Systems } \\
\text { [Stability Criteria] }\end{array}$ & 94 & 95 & 87 & 100 & 100 \\
\hline $\begin{array}{l}\text { Kinematics [Serial } \\
\text { Mechanisms] }\end{array}$ & 94 & 91 & 94 & 100 & 100 \\
\hline
\end{tabular}


FIGURE 5

STACKED BAR CHART OF TOP RATED COURSE TOPICS

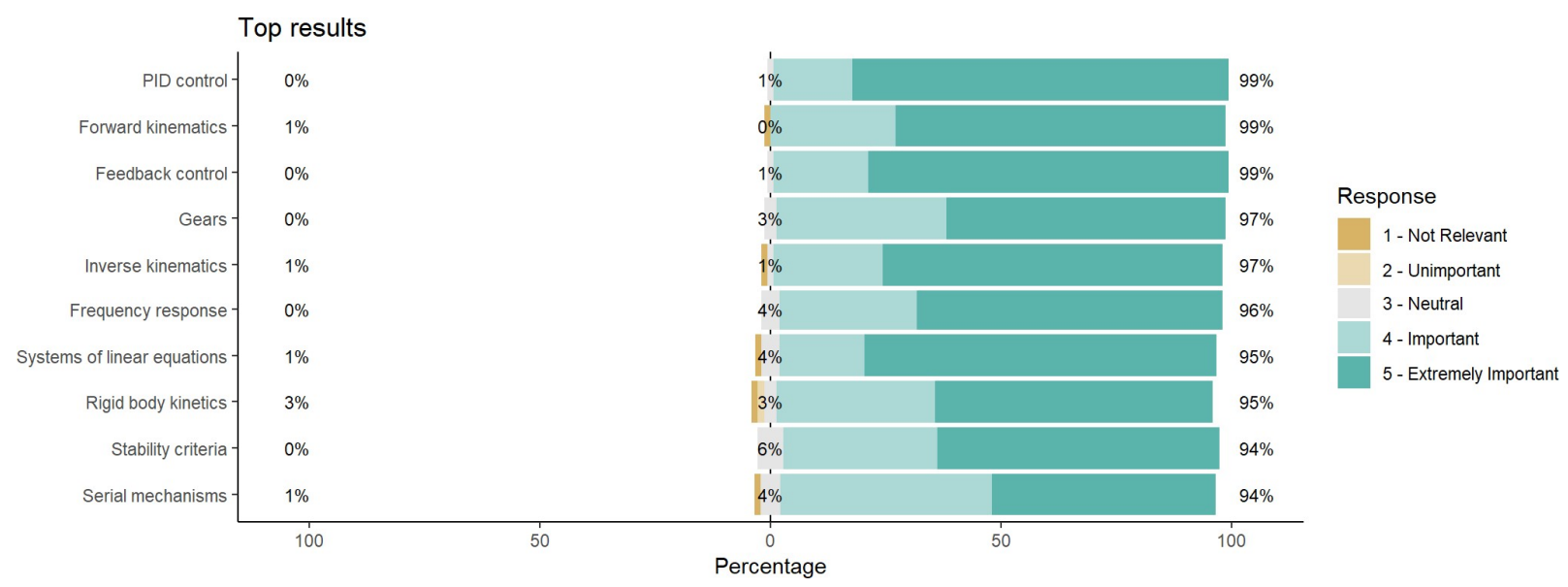

TABLE 2

TOPICS LISTED IN ORDER OF IMPORTANCE

\begin{tabular}{|c|c|c|c|c|c|c|c|c|}
\hline \multirow{2}{*}{$\begin{array}{l}\text { Course } \\
\text { Control } \\
\text { Systems }\end{array}$} & \multicolumn{8}{|c|}{ Topics listed in order of importance (left to right) for each course } \\
\hline & $\begin{array}{l}\text { PID } \\
\text { control }\end{array}$ & $\begin{array}{l}\text { Feedback } \\
\text { control }\end{array}$ & $\begin{array}{l}\text { Frequency } \\
\text { response }\end{array}$ & $\begin{array}{l}\text { Stability } \\
\text { criteria }\end{array}$ & $\begin{array}{l}\text { Block } \\
\text { diagrams }\end{array}$ & LTI Sys. & $\begin{array}{l}\text { Freq. } \\
\text { domai } \\
\mathrm{n} \\
\text { comp. }\end{array}$ & $\begin{array}{l}\text { Cont. } \\
\text { and } \\
\text { discrete } \\
\text { time } \\
\text { sys. }\end{array}$ \\
\hline Kinematics & $\begin{array}{l}\text { Forward } \\
\text { kinematics }\end{array}$ & Gears & $\begin{array}{l}\text { Inverse } \\
\text { Kinematics }\end{array}$ & $\begin{array}{l}\text { Serial } \\
\text { mech. }\end{array}$ & Machinery & $\begin{array}{l}\text { Parallel } \\
\text { mech. }\end{array}$ & & \\
\hline $\begin{array}{l}\text { Instrument. \& } \\
\text { Measurement }\end{array}$ & $\begin{array}{l}\text { Data } \\
\text { acquisition }\end{array}$ & $\begin{array}{l}\text { Error } \\
\text { Estimation }\end{array}$ & $\begin{array}{l}\text { Signal } \\
\text { conditioning }\end{array}$ & $\begin{array}{l}\text { Handling } \\
\text { digital data }\end{array}$ & $\begin{array}{l}\text { Error } \\
\text { propagatio } \\
n\end{array}$ & & & \\
\hline Dynamics & $\begin{array}{l}\text { Rigid body } \\
\text { kinetics }\end{array}$ & $\begin{array}{l}\text { Rigid body } \\
\text { Kinematics }\end{array}$ & Constraints & $\begin{array}{l}\text { 3D } \\
\text { dynamics }\end{array}$ & & & & \\
\hline $\begin{array}{l}\text { Linear } \\
\text { Algebra }\end{array}$ & $\begin{array}{l}\text { Systems } \\
\text { of linear } \\
\text { equations }\end{array}$ & $\begin{array}{l}\text { Linear } \\
\text { transf. }\end{array}$ & $\begin{array}{l}\text { Matrix } \\
\text { operations, } \\
\text { matrix } \\
\text { inverse }\end{array}$ & $\begin{array}{l}\text { Eigenvalues } \\
\text { and } \\
\text { eigenvector } \\
\mathrm{s}\end{array}$ & & & & \\
\hline $\begin{array}{l}\text { Ordinary } \\
\text { Differential } \\
\text { Eq. }\end{array}$ & $\begin{array}{l}\text { Linear \& } \\
\text { nonlinear } \\
\text { diff. eqns. }\end{array}$ & $\begin{array}{l}\text { Laplace } \\
\text { Transform }\end{array}$ & $\begin{array}{l}\text { First order } \\
\text { equations }\end{array}$ & & & & & \\
\hline $\begin{array}{l}\text { Signals, } \\
\text { Systems, \& } \\
\text { Comm. Sys. }\end{array}$ & $\begin{array}{l}\text { Fourier } \\
\text { Transform }\end{array}$ & $\begin{array}{l}\text { Filtering \& } \\
\text { filter design }\end{array}$ & $\begin{array}{l}\text { Sampling } \\
\text { theory }\end{array}$ & & & & & \\
\hline $\begin{array}{l}\text { Single } \\
\text { Variable } \\
\text { Calculus }\end{array}$ & Integrals & Derivatives & & & & & & \\
\hline Statics & Friction & $\begin{array}{l}\text { Center of } \\
\text { gravity }\end{array}$ & & & & & & \\
\hline $\begin{array}{l}\text { Numerical } \\
\text { Methods }\end{array}$ & Interpolation & & & & & & & \\
\hline $\begin{array}{l}\text { Physics } \\
\text { Mechanics }\end{array}$ & $\begin{array}{l}\text { Fixed axis } \\
\text { rotations }\end{array}$ & & & & & & & \\
\hline $\begin{array}{l}\text { Machine } \\
\text { Vision }\end{array}$ & $\begin{array}{l}\text { Motion } \\
\text { detection } \\
\text { and object } \\
\text { tracking }\end{array}$ & & & & & & & \\
\hline
\end{tabular}

The total ranking followed the trends of Faculty and Industry (57 out of 83 total respondents). Undergraduate student perceptions stood out for some course topics, e.g., PID, feedback, kinematics, 
frequency response, and linear algebra were all rated lower. In contrast, the graduate student group found most topics in the top-ten very important - nine of the top ten topics were important or very important by $100 \%$ of graduate student respondents. It should be noted that the top ten course topics come from just four course items: Control Systems (4 topics), Kinematics (4 topics), Dynamics (1 topic), and Linear Algebra (1 topic).

The top-forty ranked course topics that had received the highest combined rating of either 'extremely important' or 'important' by all respondents as a percentage of the five available choices for each topic are shown in TABLE 2. The courses are listed in decreasing order of the number of important topics in each course item. For each course listed in the table, the topics are listed in order of importance from left to right as ranked by the survey. The results show that twelve courses cover these forty topics; just three courses (Control Systems, Kinematics, and Instrumentation and Measurement) cover nineteen of these topics. While the analysis was limited to the top forty topics in this paper, more detailed analysis can help identify important courses to include in MRE curriculum.

\section{Course Items That Were Rated Least Important}

Respondents ranked the following course topics as unimportant (in descending order of mean importance score; 5 is highest, 1 is lowest): ceramics, combustion, periodic table, power and refrigeration cycles, phases and phase diagrams, chemical bonding, intermolecular forces, water- vapor mixtures, atomic structure, and stoichiometry. These results are depicted in FIGURE 6. These topics are typically covered in Chemistry, Material Science, and Thermodynamics courses.

\section{FIGURE 6 \\ COURSE TOPICS RANKED LEAST IMPORTANT}

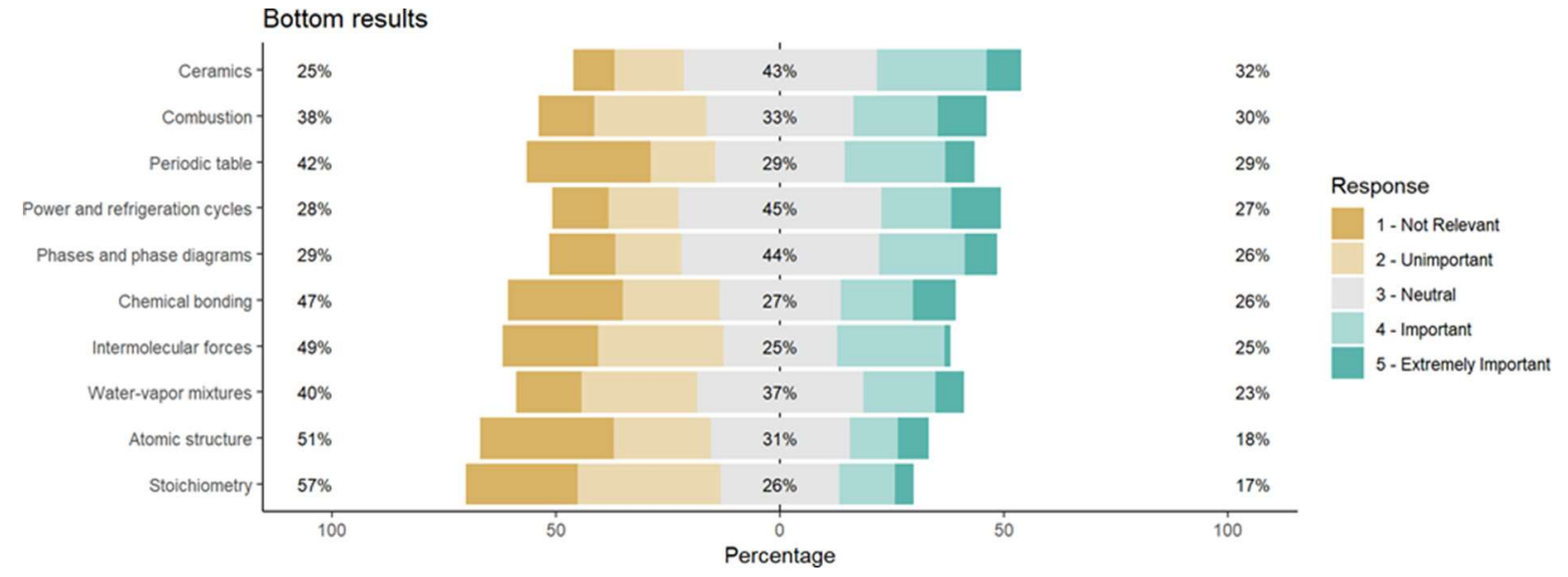

Computational Vs. Analytical Approaches

Subjects were asked to rate the following statement:

"The engineering science component of a mechatronics and robotics curriculum should emphasize modern computation techniques instead of analytical solution techniques."

The responses to this statement are graphically depicted below in FIGURE 7. 


\section{FIGURE 7 \\ IMPORTANCE OF COMPUTATIONAL VS. ANALYTICAL TECHNIQUES}

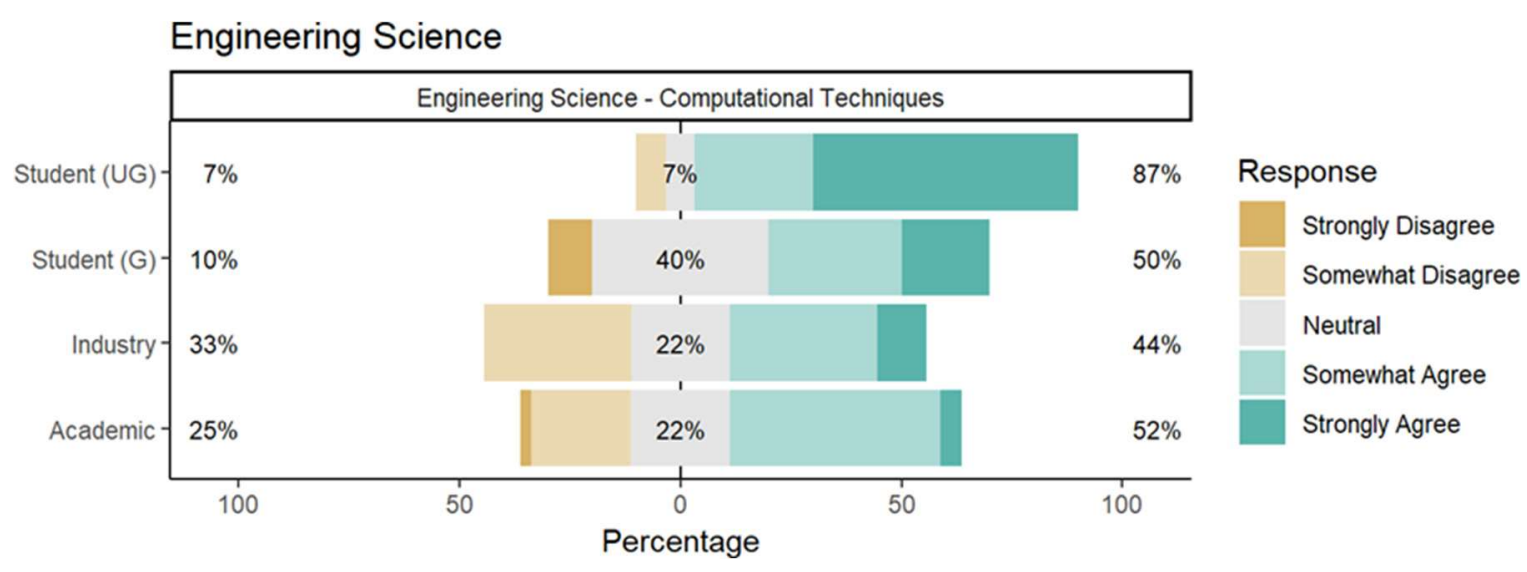

The undergraduate students answered the question about engineering science and computational techniques with a statistically significant difference (multiple linear regression, $p=0.003137$ ) from the remaining participant types. The undergraduate mean response is 1.1 points (on the 5-point Likert scale) more in favor of the statement than academics. The survey failed to establish a significant difference between academics, industry members, and graduate students on this question, with the mean response of academics at 3.3, which is almost neutral. These results are perhaps not surprising as undergraduate students, who are likely digital natives, may recognize the increasing necessity of computational techniques over survey participants with a traditional perspective having more experience in academia.

\section{Survey Respondent Comments}

In addition to scoring mechatronics concepts, the survey asked the following two questions to the respondents:

1. "Are there any other concepts that you think we missed? How would you rank them?"

2. "Any additional thoughts about compiling key concepts for mechatronics and robotics education that you would like to share?"

Regarding the first question, the respondents provided these additional concepts and areas:

- manufacturing (rapid prototyping)

- electromagnetic capability

- modeling and simulation

- state-space control

- robotic concepts

- digital image processing

- laser technology

- virtual reality

- algorithm design and debugging

- discrete mathematics

- sensor properties and selection

- industrial standards
- CAD \& CAM

- Internet of Things

- pneumatics and hydraulics control

- interfacing with and programming micro- controllers

- onboard communication (i2C, SPI, etc)

- mechatronics system design

- autonomous systems

- project management

- social privacy

- ethics \& social implications

The concepts provided by the respondents expand our mechatronics key concepts in multiple directions, including manufacturing, advanced robotic, control and signal processing techniques, discrete mathematics, critical skills for microcontrollers and mechatronic system designs, and professional skills such as project management. Some of the provided concepts, such as onboard communication (i2C, SPI, etc.), were expected to be covered by the "asynchronous serial communication" and "synchronous communication" concepts in the survey, although we did not make "i2C" and "SPI" explicit. Similarly, concepts involved 
in "interfacing with and programming microcontrollers" were expected to be covered in the "Embedded systems" and programming-related topics in the survey.

Respondents also commented on the relevance of mechatronic concepts to different specific application domains. For example, it was mentioned that various robot applications may require different or specialized mechatronics concepts. Cycle time and economics are huge driving factors for effective robotic applications. Below are some insightful responses to the second question:

- "The trouble with Mechatronics/Robotics is that they are interdisciplinary, but a student shouldn't be expected to complete more credit hours than a traditional engineering degree. I think the core competency of a mechatronics/robotics engineer should be system design, including the selection of components and interfaces as well as the design of a control sys- tem. The remainder of their curriculum should be the core classes of mechanical, electrical, computer, and software engineering"

- "Emphasis should be on the education and theory with laboratory practice and intern- ships for practical applications"

- "Focus on advanced programming knowledge and coding skills (e.g., C++) and provide a better introduction to Linux and ROS (Robotic Operating Systems)"

- "A closer tie to industry is beneficial to mechatronics programs as it will bring in more participation and projects from companies"

- "Understanding safety features and standards of different industrial robots is also very relevant"

\section{Survey Results by Course Item}

FIGUREs 8 - 12 show the Likert response results from the various course items. The aggregate Likert responses are also provided in the Appendix in FIGURE 13.

\section{FIGURE 8 \\ ENGINEERING COURSES PART 1}

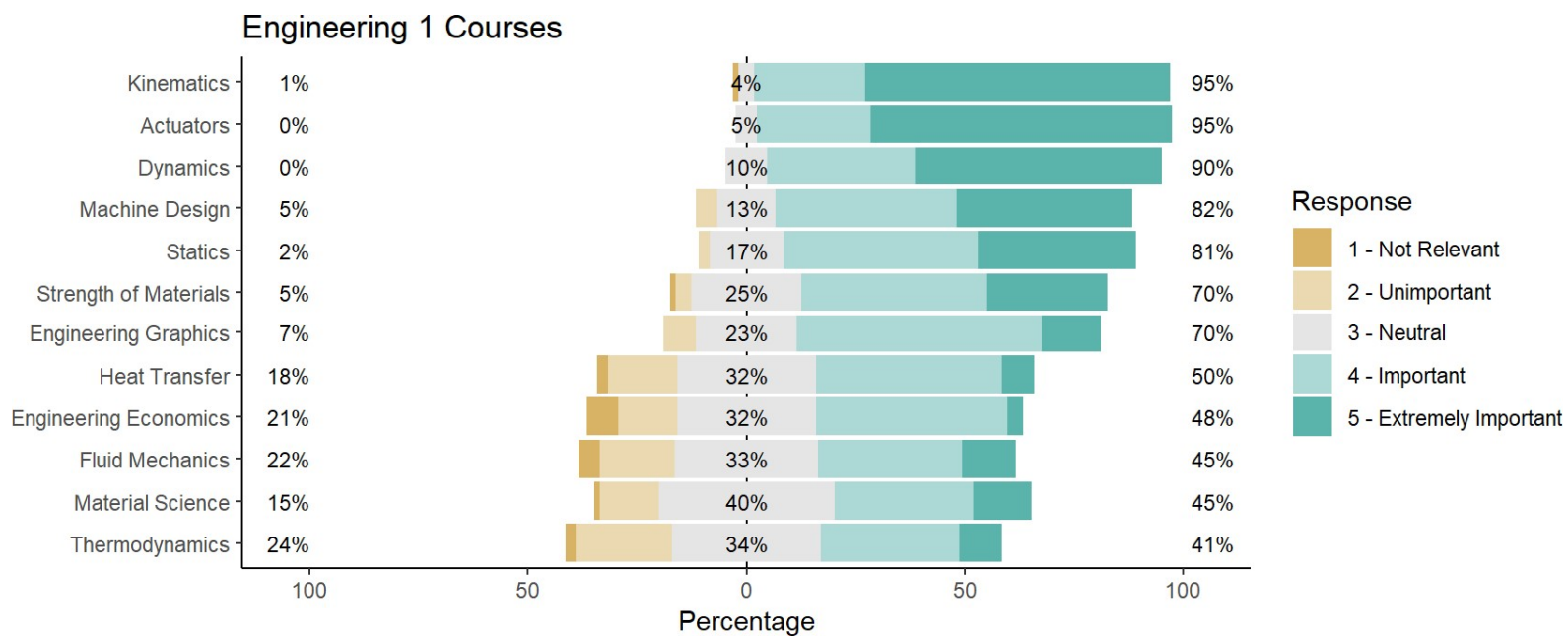


FIGURE 9

ENGINEERING COURSES PART 2
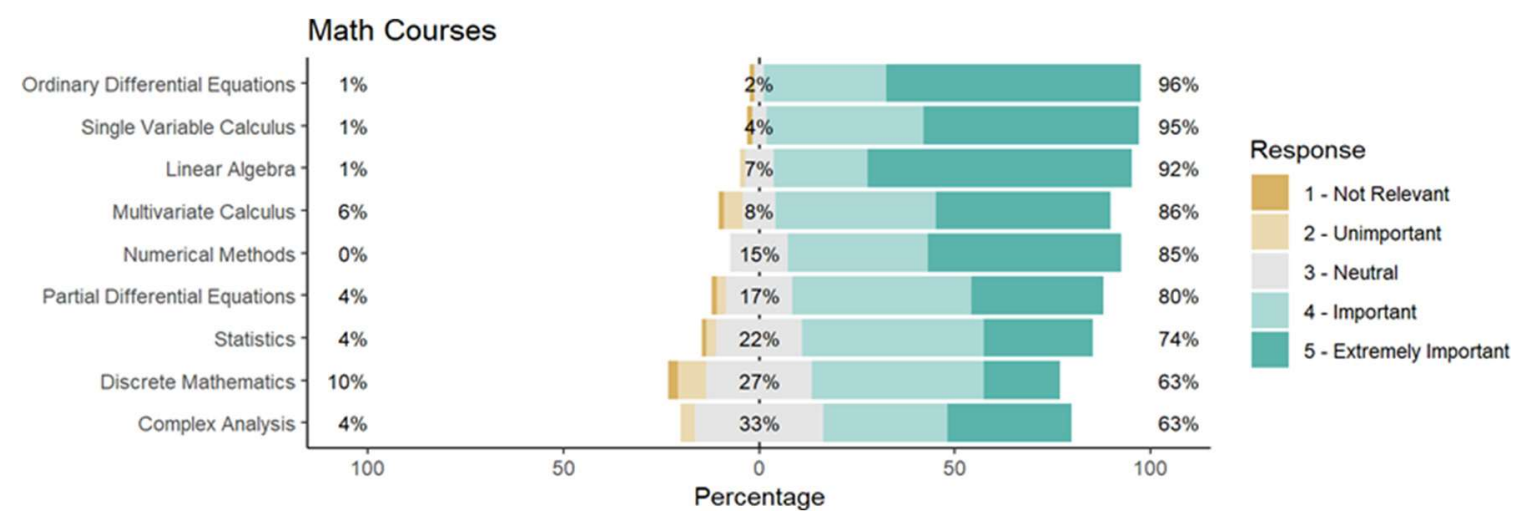

FIGURE 10

ENGINEERING COURSES PART 3
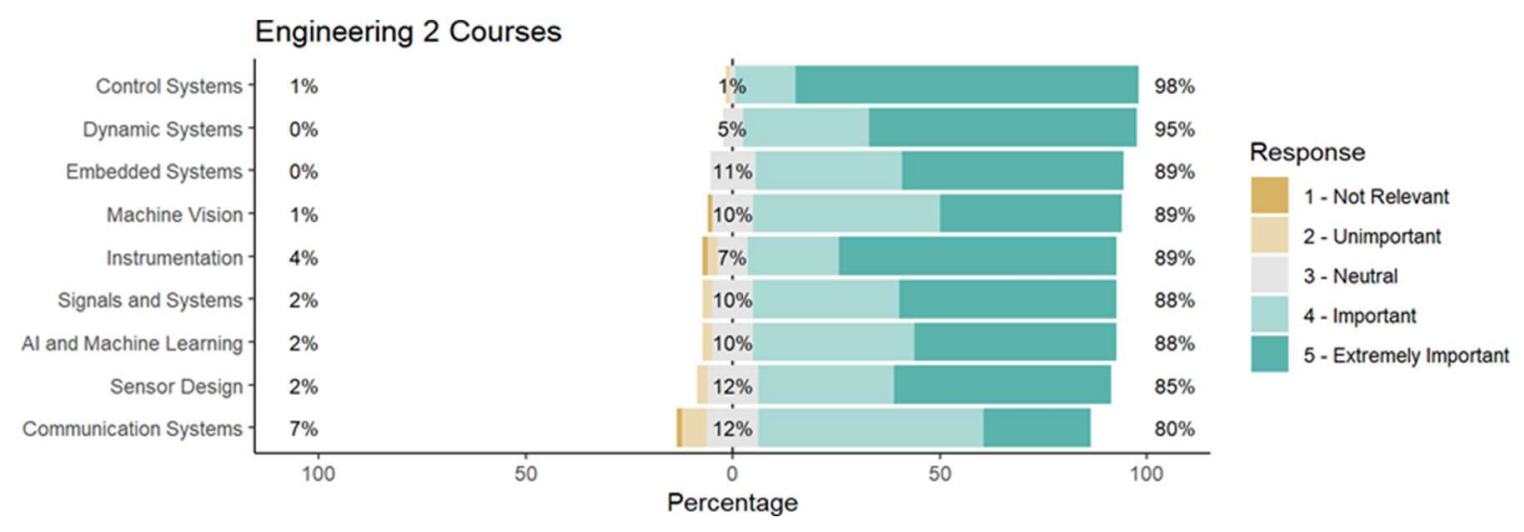

FIGURE 11

BASIC MATHEMATICS

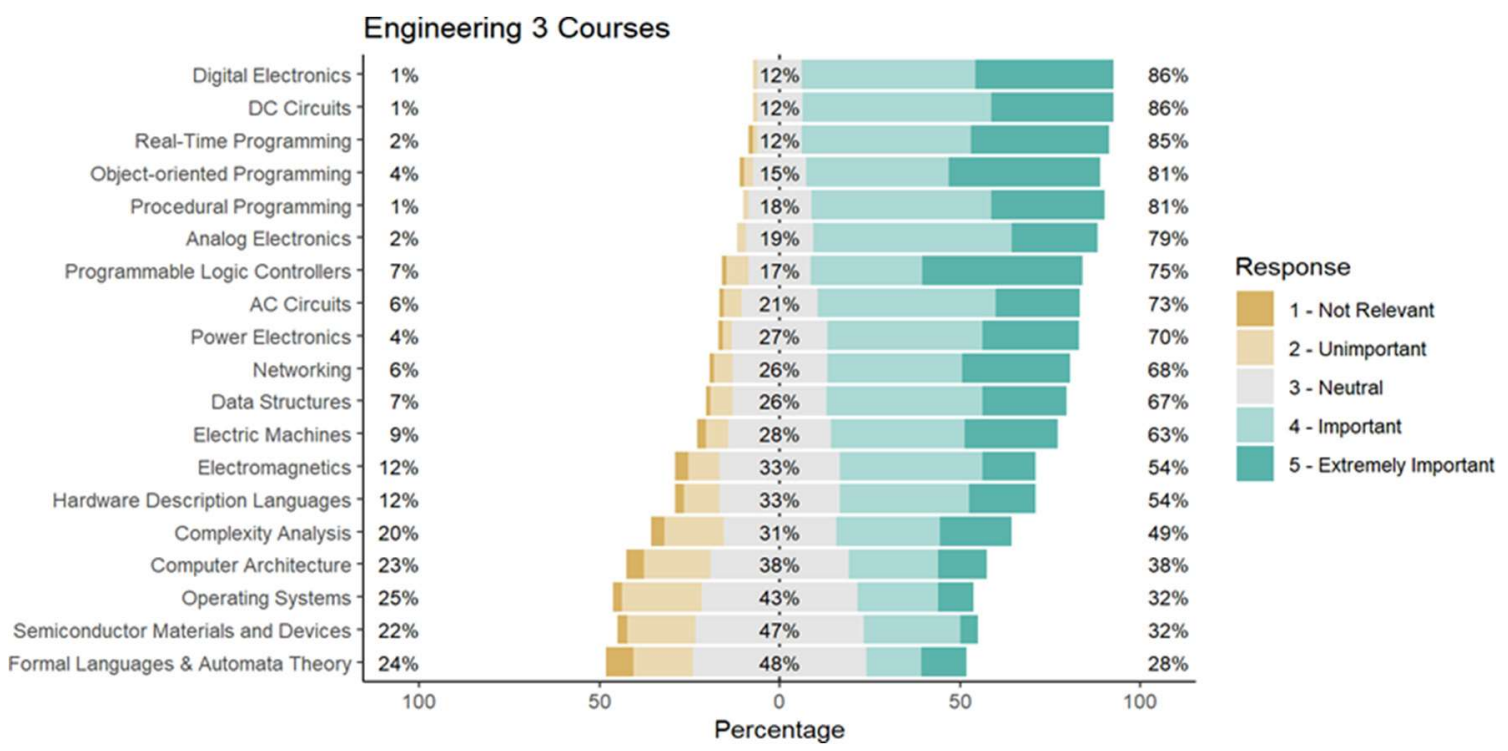




\section{FIGURE 12 \\ BASIC SCIENCE}

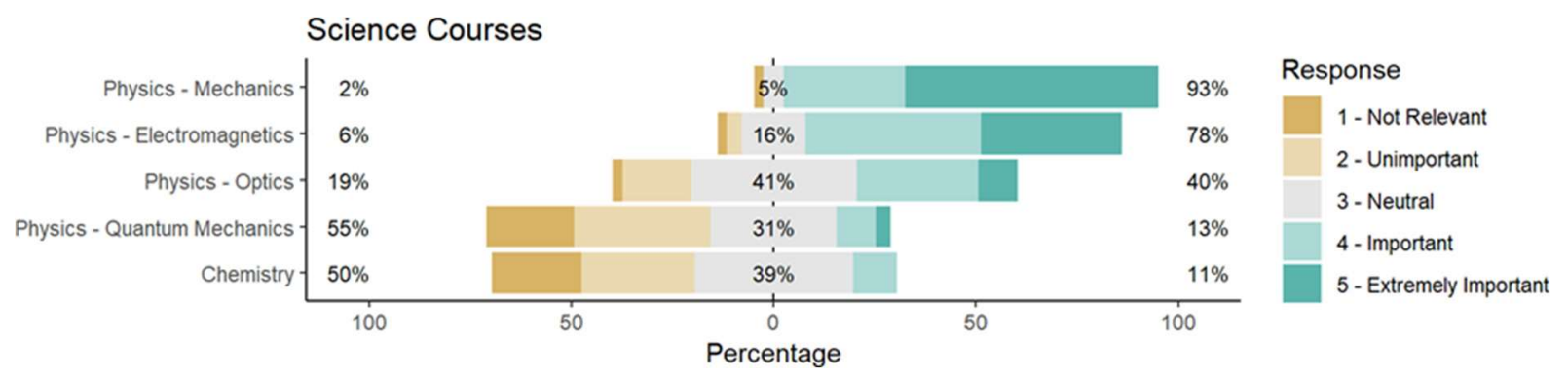

\section{DISCUSSION}

The survey collected input from important stakeholders (faculty, industry, and graduate/undergraduate students) regarding courses and course items important for an MRE curriculum. As expected for an interdisciplinary field like MRE, a great many course items were rated important by respondents. This makes developing MRE curricula including all the requisite content challenging within the constraints of a typical baccalaureate engineering degree. The central tenants of the MRE curriculum are summarized by an astute respondent who commented: "the core competency of a mechatronics/robotics engineer should be system design, including the selection of components and interfaces as well as the design of a control system."

At least for the ten top-rated course items in FIGURE 5, which heavily emphasize control systems and kinematics, there was not a substantial difference in the percentage rating among the different groups taking the survey, indicating an agreement on the importance of these topics. Control Systems and Kinematics courses therefore rank as the most important in MRE curricula. In fact 19 of the top 40 highest ranked course items are typically covered in these two courses and Instrumentation and Measurement. An additional nine courses (see TABLE 2) comprise all of the top 40 course items, rounding out the central core of MRE curricula. On the other hand, chemistry, material science, and thermodynamics topics were found to be the least relevant for inclusion in MRE programs.

The results of this survey shed light on the important (and less important) courses and/or course items to include in MRE curricula. This serves as a foundation from which to inform the discussion surrounding creation of new MRE programs and modification of existing ones. Note that the survey used in this work did not distinguish between mechatronics and robotics, rather lumping them together as a single field. How to differentiate the two is itself an ongoing discussion, and developing key concepts for each separately may arrive at different conclusions. The MRE community will certainly explore and debate such questions as programs in mechatronics and robotics become increasingly widespread.

\section{ACKNOWLEDGEMENT}

(C)2020 American Society for Engineering Education. ASEE Annual Conference Proceedings, June 2020, Virtual Conference

\section{REFERENCES}

Alciatore, D.G., \& Histand, M.B. (2001). Integrating mechatronics into a mechanical engineering curriculum. IEEE Robotics Automation Magazine, 8(2), 35-38. https://doi.org/10.1109/100.932755

Auslander, D.M. (1996). What is mechatronics? IEEE/ASME Transactions on Mechatronics, 1(1), 5-9. https://doi.org/10.1109/3516.491404 
Birk, A. (2011). What is Robotics? An Interdisciplinary Field Is Getting Even More Diverse [Education]. IEEE Robotics Automation Magazine, 18(4), 94-95. https://doi.org/10.1109/MRA.2011.943235

Craig, K., \& Voglewede, P. (2010). Multidisciplinary Engineering Systems Graduate Education: Master of Engineering in Mechatronics. 2010 IEEE Transforming Engineering Education: Creating Interdisciplinary Skills for Complex Global Environments, pp. 1-14. https://doi.org/10.1109/TEE.2010.5508819

Fletcher, R.W. (2014). The Development and Introduction of a New Bachelor of Science Degree in Robotics Engineering at Lawrence Technological University: A Review of the First Two Years. 24.1195.1-24.1195.22. Retrieved from https://peer.asee.org/the-development-and-introduction-ofa-new-bachelor-of-science-degree-in-robotics-engineering-at-lawrence-technological-universitya-review-of-the-first-two-years

Gennert, M.A., \& Putnam, C B. (2018, June 23). Robotics as an Undergraduate Major: 10 Years' Experience. 2018 ASEE Annual Conference \& Exposition. Retrieved from https://peer.asee.org/robotics-as-an-undergraduate-major-10-years-experience

Hsu, T-R. (1999). Development of an Undergraduate Curriculum in Mechatronics Systems Engineering. Journal of Engineering Education, 88(2), 173-179. https://doi.org/10.1002/j.21689830.1999.tb00431.x

Lyshevski, S.E. (2002). Mechatronic curriculum - retrospect and prospect. Mechatronics, 12(2), 195205. https://doi.org/10.1016/S0957-4158(01)00060-5

Manseur, R. (1997). Development of an undergraduate robotics course. Proceedings Frontiers in Education 1997 27th Annual Conference. Teaching and Learning in an Era of Change, 2(2), 610-612. https://doi.org/10.1109/FIE.1997.635874

National Center for Education Statistics. (n.d.). Detail for CIP Code 14.4201. Retrieved September 1, 2020, from https://nces.ed.gov/ipeds/cipcode/cipdetail.aspx?y=55\&cipid=89345

Salami, M., Mir-Nasiri, N., \& Khan, M. (2003). Development of Mechatronics Engineering Degree Program: Challenges and Prospects. International Journal of Engineering Education, 19(4), 537543. 


\section{APPENDIX \\ AGGREGATE LIKERT RESPONSES FOR ALL COURSE TOPICS FROM ALL RESPONDENTS}
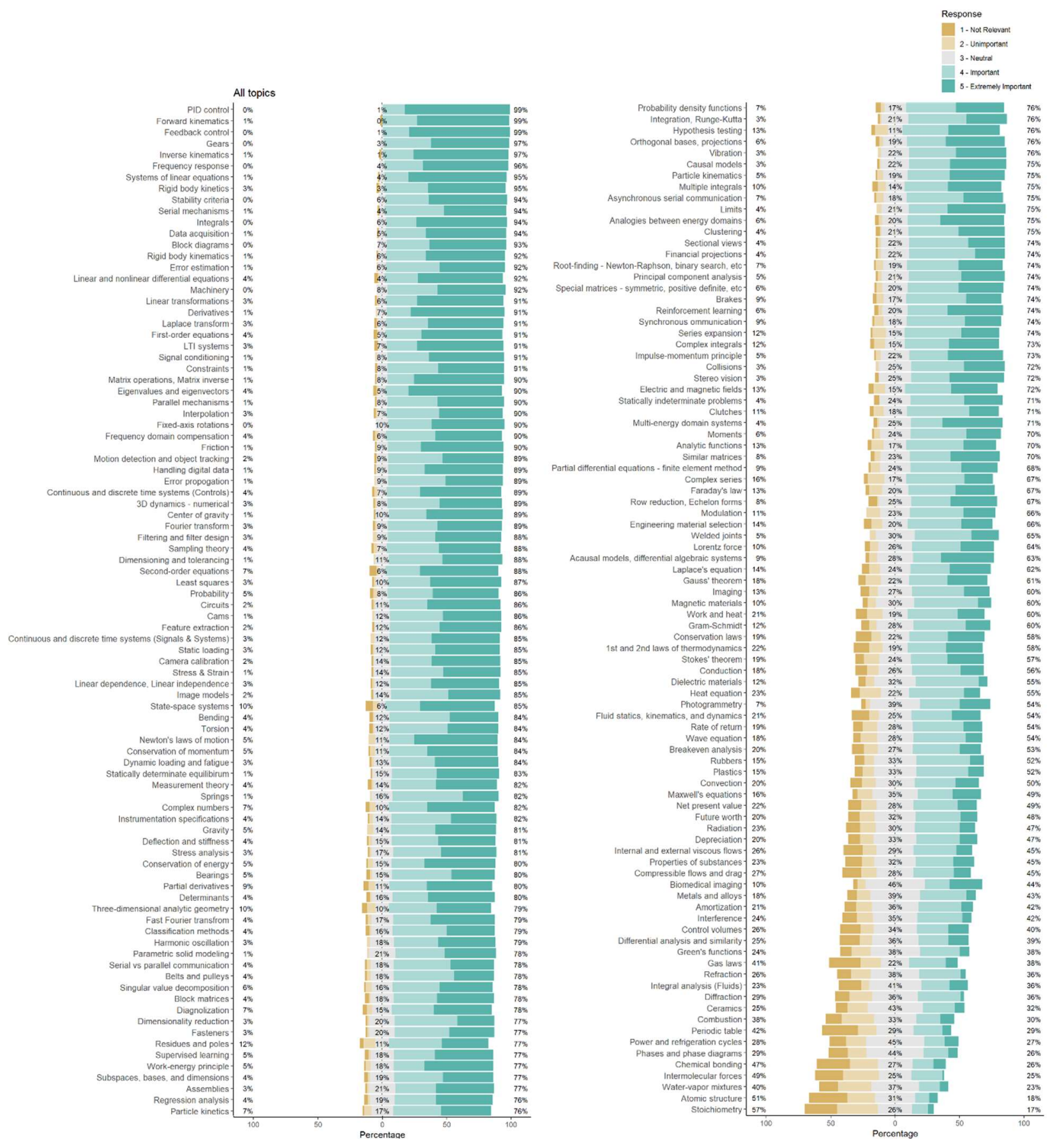